\title{
Age and Growth of An Outbreaking Acanthaster cf. solaris Population within the Great Barrier Reef
}

\author{
M. Aaron MacNeil 1,2,3,*, Karen M. Chong-Seng ${ }^{2}$, Deborah J. Pratchett ${ }^{2}$, \\ Casssandra A. Thompson ${ }^{2}$, Vanessa Messmer ${ }^{2}$ and Morgan S. Pratchett ${ }^{2}$ \\ 1 Australian Institute of Marine Science, PMB 3 Townsville MC, Townsville, QLD 4810, Australia \\ 2 ARC Centre of Excellence for Coral Reef Studies, James Cook University, Townsville, QLD 4811, Australia; \\ karen.mcs@gmail.com (K.M.C.-S.); Deborah.pratchett@jcu.edu.au (D.J.P.); \\ cassandra.thompson@my.jcu.edu.au (C.A.T.); Vanessa.messmer@gmail.com (V.M.); \\ morgan.pratchett@jcu.edu.au (M.S.P.) \\ 3 Department of Mathematics and Statistics, Dalhousie University, Halifax, NS B3H 4J1, Canada \\ * Correspondence: a.macneil@aims.gov.au or a.macneil@dal.ca; Tel.: +61-437-409-019
}

Academic Editor: Michael Wink

Received: 20 December 2016; Accepted: 8 March 2017; Published: 14 March 2017

\begin{abstract}
Despite having been studied for more than 40 years, much about the basic life history of crown-of-thorns starfish (CoTS; Acanthaster spp.) remains poorly understood. Size at age-a key metric of productivity for any animal population-has yet to be clearly defined, primarily due to difficulties in obtaining validated ages and potentially indeterminate growth due to factors such as starvation; within-population variability is entirely unknown. Here we develop age and growth estimates for an outbreaking CoTS population in Australian waters by integrating prior information with data from CoTS collected from multiple outbreaking reefs. Age estimates were made from un-validated band counts of 2038 individual starfish. Results from our three-parameter von Bertalanffy Bayesian hierarchical model show that, under 2013-2014 outbreak conditions, CoTS on the GBR grew to a $349(326,380) \mathrm{mm}$ (posterior median (95\% uncertainty interval)) total diameter at a $0.54(0.43,0.66)$ intrinsic rate of increase. However, we also found substantial evidence $(\triangle \mathrm{DIC}>200)$ for inter-reef variability in both maximum size (SD $38(19,76))$ and intrinsic rate of increase (SD $0.32(0.20,0.49))$ within the CoTS outbreak initiation area. These results suggest that CoTS demography can vary widely with reef-scale environmental conditions, supporting location-based mechanisms for CoTS outbreaks generally. These findings should help improve population and metapopulation models of CoTS dynamics and better predict the potential damage they may cause in the future.
\end{abstract}

Keywords: age estimation; Bayesian modeling; Great Barrier Reef

\section{Introduction}

Population outbreaks of crown-of-thorns starfish (CoTS; Acanthaster spp.) are a major contributor to coral loss throughout the Indo-Pacific [1-4]. On the Great Barrier Reef (GBR), for example, there have been four distinct episodes of outbreaks since the 1960s [5], and coral loss caused by these outbreaks is equal or greater than that caused by other major disturbances (e.g., severe tropical storms and climate-induced coral bleaching [3]). Moreover, minimizing or preventing outbreaks of Acanthaster spp. is considered one of the foremost management strategies to reverse sustained coral loss on the GBR (e.g., [6]). Effective management of CoTS outbreaks is, however, currently constrained by limited knowledge of CoTS demography [5,7], which is fundamental to understanding both the proximal and ultimate causes of outbreaks [8]. 
Outbreaks of Acanthaster spp. are variously attributed to their inherent life history characteristics, such as exceptional fecundity $[9,10]$, versus anthropogenic and environmental changes that disrupt normal regulatory processes [11-13]. However, there is limited data on differences in population demographics within outbreak or non-outbreak populations of CoTS, which would help to resolve the relative importance of intrinsic versus extrinsic processes. Most studies of CoTS (e.g., [14-16]) are initiated after starfish densities have already increased to outbreak levels, and demographic information is largely limited to estimates of abundance and size structure. Some studies have used size structure to estimate age structure, and thereby reconstruct the events that led to the particular outbreak (e.g., $[17,18])$, and resolving when and where CoTS outbreaks are initiated is fundamental for establishing potential causes or triggers for outbreaks [13]. However, the relationship between size and age for CoTS may be obscured by vagaries in growth due to food availability and environmental conditions $[19,20]$, leaving an important gap in our ability to quantify demographic rates from size alone.

Size-independent proxies of individual age have been explored, including spine length, age pigments, and growth-ring-like pigment bands on spines [21], with the most promising technique for estimating individual ages based on pigment banding [22]. Validation of band counts has been made for some younger age classes (age three to five years) in a mark-recapture context, with 21 of 22 recaptured individuals having added a single growth band after 12 months at liberty on Davies Reef, Australia [23], and evidence of spine growth (mean \pm SE $0.72 \pm 0.08 \mathrm{~mm}$ in eight months) via tetracycline markers present in 85 recaptured individuals $15.5-46.5 \mathrm{~cm}$ with estimated ages of one to nine years [24]. However, much about the relationship between size and age in CoTS remains unknown, including the exact mechanism by which banding occurs. However, seasonality in the reproductive physiology and life history of CoTS on the GBR is a strong candidate [25].

The current outbreak of CoTS on the GBR was first spotted in 2011, near Lizard Island in the northern management sector [26]. Given repeated association with the initiation of outbreaks $[13,17,27,28]$ in the area between Lizard Island (14.7 S) and Cairns (16.9 S), this region has been dubbed the CoTS 'initiation box' and is subject to intense surveillance and research (Figure 1). To explore potential inter-reef variability in CoTS demographics within this critical area, we undertook pigment banding of wet CoTS spines to estimate size at age for CoTS collected among reefs within or near the initiation box, using a Bayesian hierarchical approach.

\section{Materials and Methods}

A total of 3759 CoTS were collected between October 2013 and September 2014 from four to five reefs within each of four different sub-areas of Australia's Great Barrier Reef (Table 1). All starfish were collected while snorkeling or diving using hooks and poles. Starfish were kept alive in $500 \mathrm{~L}$ tanks connected to high flow-through sea-water systems on live-aboard boats or at the research station on Lizard Island for a maximum of $20 \mathrm{~h}$ before being processed. During processing, starfish were removed from the water and placed on flat surface for 30-90 s before measuring maximum diameter along two perpendicular axes. Ages were estimated from a total 2038 CoTS based on sampling of replicate spines from a maximum of 200 starfish per reef (Table 1), for individuals from which we could extract band counts. For those individuals selected for inclusion in demographic analyses, the longest spine from the upper portion of each of three to six arms (close to the disc) was removed and stored dry for later processing. Spines were soaked in $5 \mathrm{~mL}$ of $10 \%$ sodium hypochlorite solution for a minimum of $2 \mathrm{~h}$ to remove tissue. The spines were then thoroughly rinsed with fresh water and then soaked in freshwater for a minimum of $3 \mathrm{~h}$ before visually inspecting banding patterns (Figure 1), following [22]. Age readers recorded both the number of distinct bands observed on each spine, as well as a subjective quality score $\left(Q_{\text {score }}\right)$ between 0 (unreliable) and 1 (highly reliable) that reflected their belief in their ability to resolve clear individual bands. 

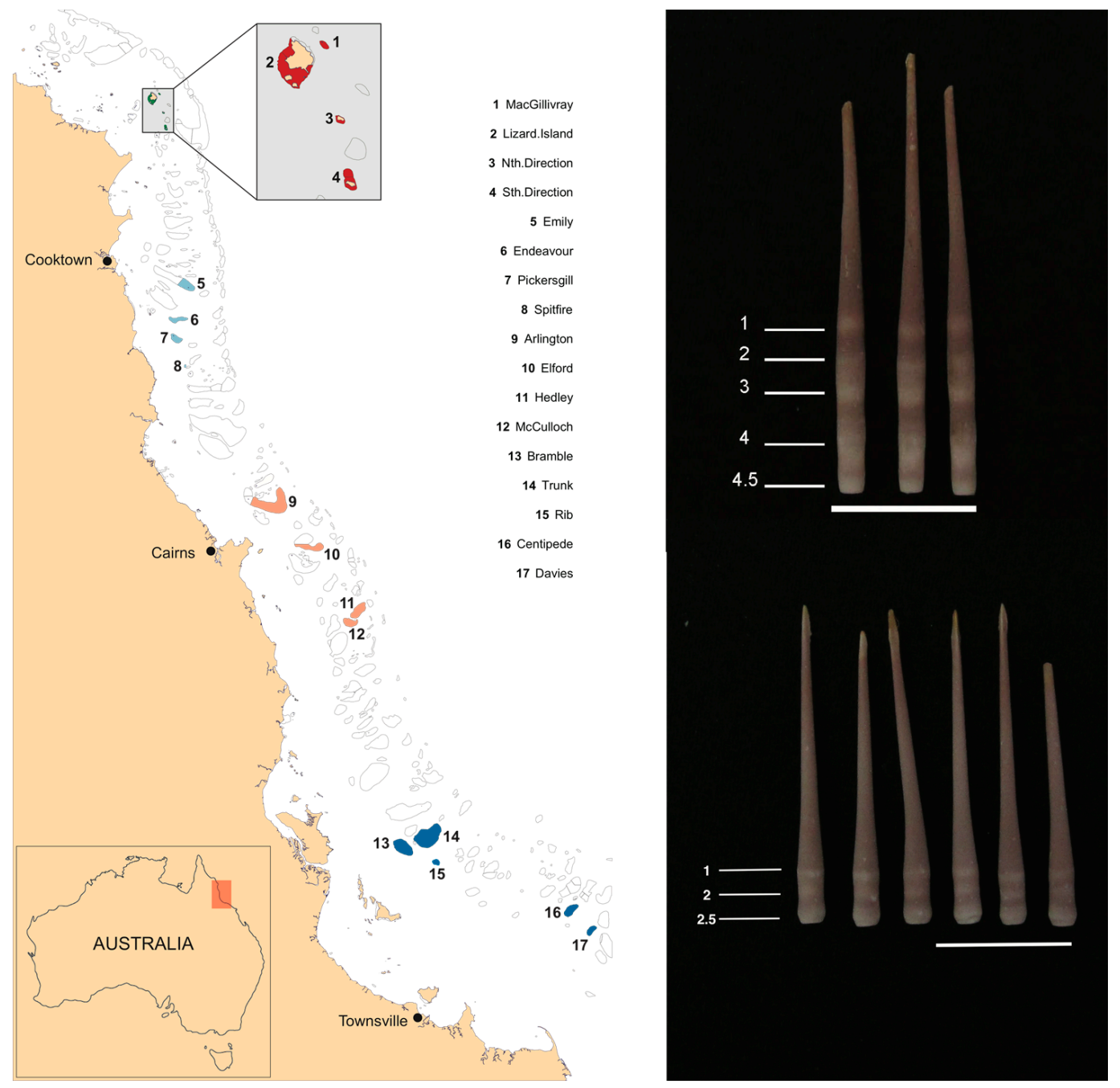

Figure 1. Great Barrier Reef study region reefs sampled for crown-of-thorns starfish (CoTS; Acanthaster spp.), October 2013 and September 2014 (left panel). Reefs are colored according to region. Spines selected for band counting from two starfish (right panels), showing distinct banding counts from 1 to 4.5 (top panel) and 1 to 2.5 (bottom panel), scale bar represents $1 \mathrm{~cm}$.

Table 1. Summary table of collections of crown-of-thorns starfish on the GBR between October 2013 and November 2014. Only a subset of starfish ( $\leq 202$ individuals per reef) was used in demographic analyses.

\begin{tabular}{|c|c|c|c|c|}
\hline Region & Reef & Reef Size $\left(\mathbf{k m}^{2}\right)$ & $n$ (Abundance) & $n$ (Demographics) \\
\hline \multirow{5}{*}{$\begin{array}{l}\text { Northern sector of the } \\
\text { initiation box (around } \\
\text { Lizard Island) }\end{array}$} & Lizard Island & 13.62 & 333 & 202 \\
\hline & MacGillivray Reef & 0.92 & 333 & 200 \\
\hline & North Direction & 0.69 & 305 & 198 \\
\hline & South Direction & 3.32 & 259 & 200 \\
\hline & Total & & 1230 & \\
\hline \multirow{5}{*}{$\begin{array}{l}\text { Central sector of the } \\
\text { initiation box } \\
\text { (off Cooktown) }\end{array}$} & Emily Reef & 35.31 & 348 & 200 \\
\hline & Endeavour Reef & 20.40 & 340 & 200 \\
\hline & Pickersgill Reef & 18.82 & 322 & 200 \\
\hline & Spitfire Reef & 3.12 & 300 & 200 \\
\hline & Total & & 1310 & \\
\hline
\end{tabular}


Table 1. Cont.

\begin{tabular}{|c|c|c|c|c|}
\hline Region & Reef & Reef Size $\left(\mathrm{km}^{2}\right)$ & $n$ (Abundance) & $n$ (Demographics) \\
\hline \multirow{5}{*}{$\begin{array}{l}\text { Southern sector of the } \\
\text { initiation box (off Cairns) }\end{array}$} & Arlington Reef & 127.75 & 334 & 200 \\
\hline & Elford Reef & 39.68 & 89 & 89 \\
\hline & McCulloch Reef & 26.31 & 308 & 200 \\
\hline & Hedley Reef & 39.84 & 328 & 200 \\
\hline & Total & & 1059 & \\
\hline \multirow{7}{*}{$\begin{array}{l}\text { Southern edge of the } \\
\text { outbreak (off Townsville) }\end{array}$} & Bramble Reef & 62.99 & 75 & 75 \\
\hline & Centipede Reef & 30.01 & 4 & 4 \\
\hline & Davies Reef & 16.62 & 3 & 3 \\
\hline & Rib Reef & 10.45 & 36 & 36 \\
\hline & Trunk Reef & 121.60 & 42 & 42 \\
\hline & Total & & 160 & \\
\hline & Grand Total & & 3759 & \\
\hline
\end{tabular}

\section{Statistical Methods}

We estimated the size-at-age relationship for CoTS from around the initiation box using a three-parameter formulation of the von Bertalanffy growth model, implemented in a Bayesian framework. The basic von Bertalanffy model defines growth relative to length as:

$$
L_{t}=L_{\infty}-\left(L_{\infty}-L_{0}\right) e^{-k t}
$$

where $L_{t}$ is length-at-age $t$ (typically in years, in our analysis the band counts), $\boldsymbol{L}_{\infty}$ is the maximum size, $k$ is a growth coefficient and $L_{0}$ is the length-at-age zero. For our analysis, we modified this basic form to reflect specific dependencies in the data, with the various $L$ parameters corresponding to CoTS diameters. Specifically, the model was parameterized as:

$$
\begin{gathered}
D I A_{i} \sim N\left(\mu_{i}, \sigma_{o b s}\right) \\
\mu_{i}=L_{\infty r}-\left(L_{\infty r}-L_{0}\right) e^{-k_{r} l C_{i}} \\
I C_{i} \sim N(5,100) \\
C_{i, o} \sim N\left(l C_{i}, \sigma_{c} / Q_{s c o r e, i, o}\right) \\
k_{r} \sim N\left(k, \sigma_{k}\right) \\
L_{\infty r} \sim N\left(L_{\infty}, \sigma_{L}\right) \\
\sigma_{o b s}, \sigma_{k}, \sigma_{L}, \sigma_{c} \sim U(0,1000) \\
k \sim N(0.235,0.303) \\
L_{\infty} \sim N(562.7,37.6) \\
L_{0} \sim N(0.83,2.11)
\end{gathered}
$$

where $D I A_{i}$ was the observed diameter of an individual CoTS from reef $r$, and $C O U_{i}$ was the wet band count recorded by a single age reader. The $l C_{i}$ parameter was an estimated latent band count for each individual CoTS, given the observed count from each reader $\left(C_{i, o}\right)$ and an estimated standard deviation scaled by their subjective quality scores $\left(Q_{s c o r e, i, o}\right)$. The $\sigma$ parameters represent standard deviations. This approach allowed us to build on previous size at age data (from Figure 5 of [5]; model results presented in Supplemental Table S1); explicitly integrate band counts and quality scores; and hierarchically estimate reef-scale demographics based on sub-populations collected from individual 
reefs. Models were coded using the PyMC3 framework [29] in Python, with inferences made using gradient-based Hamiltonian MCMC sampling in the form of a No-U-Turn Sampler (NUTS). The NUTS sampler is particularly appropriate for efficient sampling when parameters are highly correlated, as is common between parameters $L_{\infty}$ and $k$.

Given that we lacked a validation approach for the wet band counts used for inference, we undertook an inter-reader comparison between the main age reader and a second age reader, both of whom read a sub-group of spines using a dry band count method. The dry band counts were used initially by both readers before switching to the wet count method that readers felt better resolved individual bands. A solitary reader then wet band counted the full set of 2038 starfish from which spines had been collected. We calculated within-reader variability, relative to the other, taking $95 \%$ percentiles overlapping with zero as lack of evidence for individual reader bias. It is important to note that this approach did not validate the ages reported, but demonstrated reliability of band counts.

\section{Results}

\subsection{Age and Growth Estimates}

Overall, the estimated maximum size of CoTS within the current outbreak was a $349(326,380)$ $\mathrm{mm}$ (posterior median (95\% uncertainty interval)) total diameter, with an average $0.54(0.43,0.66)$ intrinsic rate of increase. However, the observed distribution of CoTS collected had a median size of a $285(150,400)(95 \%$ quantiles) mm diameter, with median band counts at age four, putting $93 \%$ of the data below age eight, where sizes begin to asymptote. Despite this, the reef-scale hierarchical model estimates showed a good fit to the observed data (Figure 2), capturing apparent reef-level differences in growth that were well supported compared with an alternative model that did not include the reef-level hierarchical structure $(\Delta \mathrm{DIC}>200)$.
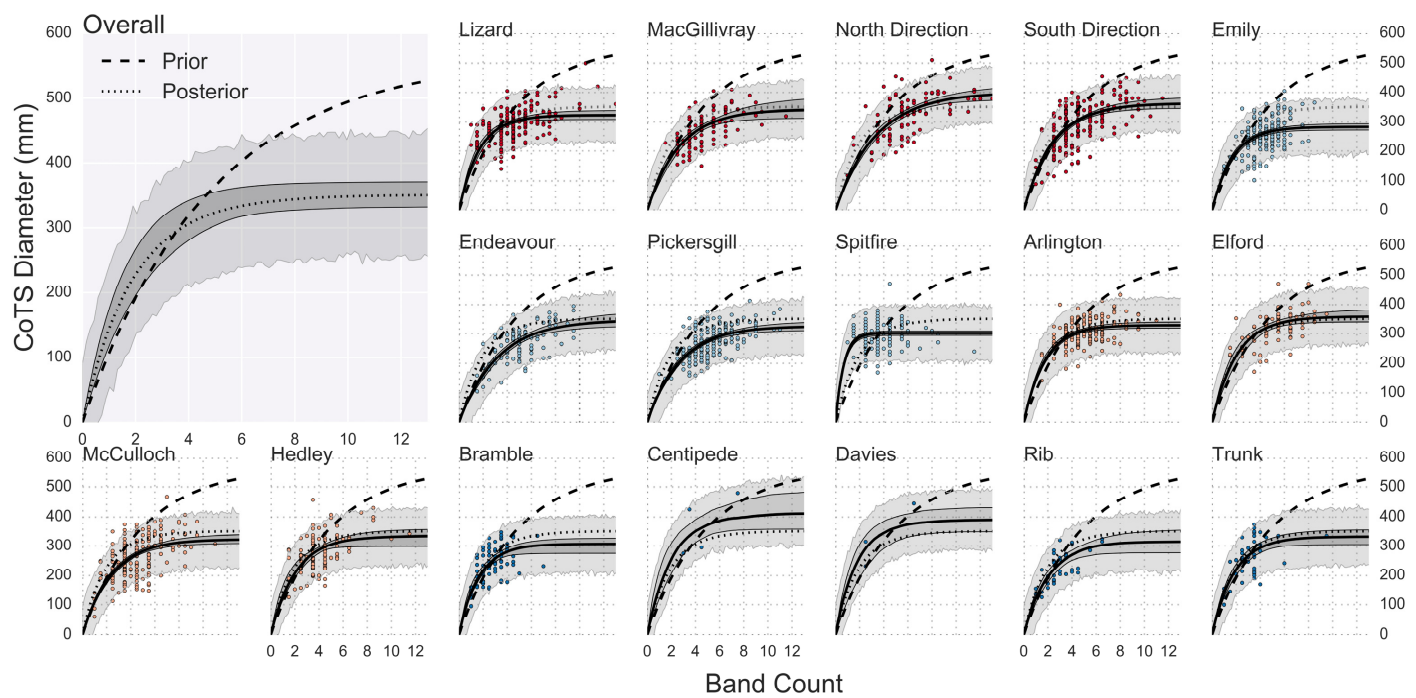

Figure 2. Bayesian hierarchical von Bertalanffy model posterior fit for the relationship between band counts and observed diameter of CoTS collected in the Great Barrier Reef CoTS initiation box, 2013-2014. Overall (grey panel, upper left) hierarchical posterior median von Bertalanffy curve (dotted line), 50\% (dark grey area), and 95\% (light grey area) uncertainty intervals (given highest posterior density); overall prior curve (dashed line) is from previous age and growth studies reported in [5]. Hierarchical model fits for each study reef (white panels) show inter-reef variation in posterior median curved (black lines) and uncertainty intervals, with points representing samples from the northern initiation box (red), central initiation box (light blue), southern initiation box (tan), and southern outbreak edge (dark blue). 
Inter-reef variation in both $L_{\infty}$ and $k$ was substantial, with non-overlapping $95 \%$ uncertainty intervals both within and among sampling regions (Figure 3). As expected, the correlation between $\boldsymbol{L}_{\infty}$ and $\boldsymbol{k}$ was high, averaging -0.78 among reefs; however, posterior traces from the NUTS algorithm showed no evidence for lack of convergence and the overall (global) $L_{\infty}$ and $k$ estimates were uncorrelated (-0.01). Individual reef estimates for $\boldsymbol{L}_{\infty}$ ranged between $283 \mathrm{~mm}$ (Emily Reef) and $415 \mathrm{~mm}$ (Centipede Reef), with the majority lying around $340 \mathrm{~mm}$; reef estimates of $k$ ranged between 0.30 (North Direction Reef) and 1.5 (Spitfire Reef), averaging 0.54 overall.
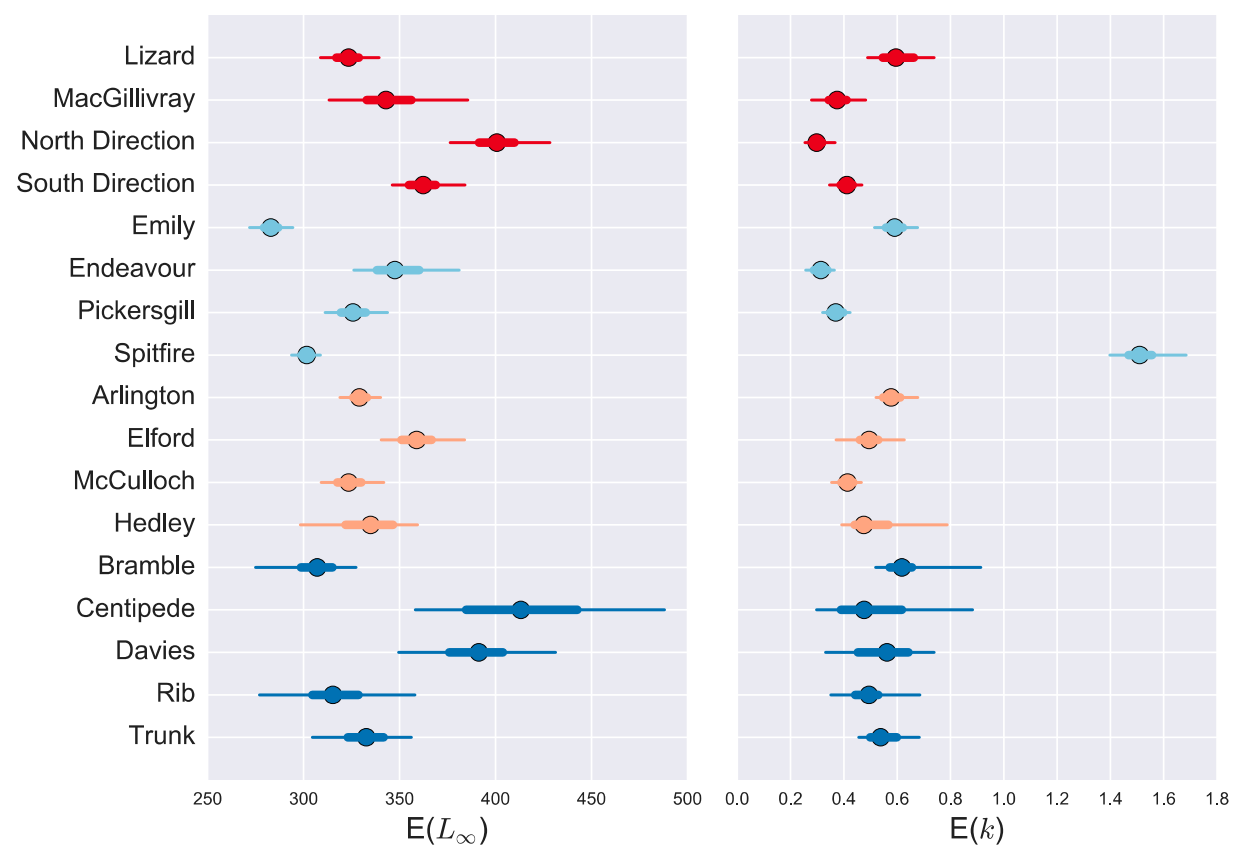

Figure 3. Bayesian hierarchical von Bertalanffy parameter posterior effect sizes for the relationship between band counts and observed diameter of CoTS collected in the Great Barrier Reef CoTS initiation box, 2013-2014. Points are highest posterior density medians, with 50\% (thick lines) and 95\% (thin lines) uncertainty intervals. Plot includes reefs sampled from the northern initiation box (red), central initiation box (light blue), southern initiation box ( $\tan$ ), and southern outbreak edge (dark blue).

\subsection{Age Reliability}

Dry band counts between agers A and B were broadly comparable, with equivalent average counts between ages two to seven, and a slight underestimation by ager B, relative to A, above age eight (Supplemental Figure S1); this relative discrepancy was less pronounced in estimates of ager A relative to B. Therefore, we found no suggestion of reader-specific bias in CoTS dry band counts across the range of assessed ages.

\section{Discussion}

The demography of Acanthaster spp. is considered to be extremely plastic, whereby adult growth and longevity are strongly dependent on local environmental conditions, such as food availability, temperature, and wave exposure $[19,20,30]$. For this reason, the relationship between size and age (and the capacity to reliably assign starfish to a given cohort based on size) has been highly contentious. Our results provide substantial support for this theory, with the demography of age and growth varying substantially among closely related reefs and at varying stages of outbreak. Most notably, the asymptotic size of CoTS sampled across the 17 reefs in the northern GBR ranged from a $<300 \mathrm{~mm}$ total diameter at Emily Reef to a $>400 \mathrm{~mm}$ total diameter at North Direction. 
Inter-reef variation in the life history of $A$. cf. solaris within the northern GBR, during the latest outbreak, is likely due to extrinsic factors (e.g., local environmental settings) rather than intrinsic population processes. Notably, extensive genotyping of the same CoTS sampled for this study found no genetic structure among reefs [31], suggesting that all starfish sampled are highly related and have a common origin. Variation in growth is unlikely, therefore, to have any genotypic basis. More relevant is the local density of Acanthaster spp. and the stage of the outbreak at each reef, whereby high asymptotic sizes ( $\boldsymbol{L}_{\infty}$ ) occur at reefs (Centipede Reef and Davies Reef) with low abundance of CoTS, especially relative to the size of the reefs. Moreover, outbreaks are yet to become established at these locations, such that the larger CoTS sampled have likely grown up with very limited competition for food. At high densities (during outbreaks), Acanthaster spp. appear to have highly constrained, finite growth and survivorship, which has been linked to strong intraspecific competition and rapid depletion of prey resources [32]. The smaller $L_{\infty}$ estimates from this study come from reefs (e.g., Lizard Island, Emily Reef and Spitfire Reef) where outbreak densities have been well established for several years. The smallest asymptotic sizes recorded during this study also correspond with modal sizes of CoTS recorded (300-350 $\mathrm{mm}$ total diameter) during established outbreaks on the GBR in the 1990s [17,33].

Despite inter-reef differences in the demography of CoTS, the general pattern of growth is characterized by rapid initial growth (when starfish are one to three years of age), followed by decelerating growth approximately three to four years post-settlement, and finally, an extended period of very limited growth (Figure 2). This is consistent with determinate growth shown by [20] for individual CoTS that were reared from in vitro fertilization of gametes obtained from CoTS collected on the GBR and then maintained in captivity for eight years. However, [20] readily acknowledged that determinate growth (with asymptotic sizes of 300-400 mm TL) was inconsistent with records of very large (>750 mm) Acanthaster spp. from the GBR [23], and may have been an artifact of captivity or limited food availability. Conversely, determinate growth may occur due to the increasing diversion of energy from somatic growth to gametogenesis [34], which is consistent with disproportionate investment in reproduction with the increasing size of CoTS on the GBR [10]. Elsewhere, sustained growth of Acanthaster spp. has been documented for up to seven to 13 years [18], resulting in asymptotic sizes $>450 \mathrm{~mm}$, as used to generate priors for this study, which may have occurred due to an abundance of prey resources, limited reproductive investment, or in low density populations.

While comparisons of estimated ages across two different readers show remarkable consistency, and demonstrate reliability in band counts, this does not necessarily mean that density banding on the spines of Acanthaster spp. is an effective proxy for the age of individual CoTS. Validation of age estimates fundamentally requires absolute determination of growth increment frequency, particularly the age of initial band formation [35], which has only been conducted in a single mark-recapture study that we are aware of [25]. Because our study duration was only a single year, we were unable to validate the ages estimated. Herein, we assumed the first band count represents the start of year two, based on the reported emergence of CoTS around age two [5]. Despite this important issue, the consistent annual reproductive cycle of CoTS along the GBR $[5,25]$ suggests that our ages should be consistent with the seasonal banding previously reported from this area [23].

\section{Conclusions}

These findings point to fundamental differences in demographics of CoTS between outbreaking and non-outbreaking populations as alluded to by [8], who explained sporadic CoTS outbreaks using a bifurcated invasion model, where outbreaking populations are limited by their coral prey (a Holling Type-II functional response [36]) and non-outbreaking populations are governed by predation (a Type-III functional response). In light of our results, the implications of multi-modal population dynamics are that food-limited outbreaking populations grow more slowly and to a smaller ultimate size than those in non-outbreaking populations. Although such a mechanism remains unproven, our results emphasize that a clear understanding of variable CoTS demography under a 
range of outbreak and environmental conditions will be fundamental to understanding the underlying cause(s) of population outbreaks. That we have failed to develop these kinds of flexible population models over the past three decades of CoTS research highlights a major gap in devising effective interventions for their control.

Supplementary Materials: The following are available online at www.mdpi.com/1424-2818/9/1/18/s1, Figure S1: Inter-reader comparability for dry counts of crown-of-thorns starfish (Acanthaster cf. solaris) spines; Table S1: Posterior parameter estimates for a Bayesian von Bertalanffy three-parameter model; Table S2: Reef-specific posterior parameter estimates for a Bayesian von Bertalanffy three-parameter model; Data S1: cots_spines_wet_data.csv; Wet band count data from CoTS initiation box, 2013-2014.

Acknowledgments: We are grateful for to those who assisted us in the collection of CoTS: Kristen Anderson, Zara-Louise Cowan, Jacob Johansen, Elmar Messmer, Kirsty Nash, Laura Richardson, Robert Streit, Stuart Watson, Simon Wever; Lizard Island Research Staff Tim Godfrey; and the crew of Reef Connection and Capricorn Star. This research was supported by the Commonwealth Government of Australia, through the Caring for Country and Reef Rescue Program.

Author Contributions: M.A.M., V.M. and M.S.P. conceived and designed the experiments; K.M.C.-S., V.M. and M.S.P. collected the samples; K.M.C.-S., C.A.T. and D.J.P. processed the samples; M.A.M. analyzed the data; M.A.M. and M.S.P. wrote the paper. All authors edited the final manuscript.

Conflicts of Interest: The authors declare no conflict of interest.

\section{References}

1. Bruno, J.F.; Selig, E.R. Regional decline of coral cover in the Indo-Pacific: Timing, extent, and subregional comparisons. PLoS ONE 2007, 2, e711. [CrossRef] [PubMed]

2. Trapon, M.; Pratchett, M.S.; Penin, L. Change in coral cover and composition following 30 years of disturbances at Moorea, French Polynesia. J. Mar. Biol. 2011, 2011, 807625.

3. De'ath, G.; Fabricius, K.E.; Sweatman, H.; Puotinen, M. The 27-year decline of coral cover on the Great Barrier Reef and its causes. Proc. Nat. Acad. Sci. USA 2012, 109, 17995-17999. [CrossRef] [PubMed]

4. Pisapia, C.; Burn, D.; Yoosuf, R.; Najeeb, A.; Anderson, K.D.; Pratchett, M.S. Coral recovery in the central Maldives archipelago since the last major mass-bleaching, in 1998. Sci. Rep. 2016, 6, 34720. [CrossRef] [PubMed]

5. Pratchett, M.S.; Caballes, C.F.; Rivera-Posada, J.A.; Sweatman, H.P.A. Limits to understanding and managing outbreaks of crown-of-thorns starfish (Acanthaster spp.). Oceanogr. Mar. Biol. Annu. Rev. 2014, 52, 133-200.

6. Hoey, J.; Campbell, M.L.; Hewitt, C.L.; Gould, B.; Bird, R. Acanthaster planci invasions: Applying biosecurity practices to manage a native boom and bust coral pest in Australia. Manag. Biol. Invasion 2016, 7, $213-220$. [CrossRef]

7. Moran, P.J.; Reichelt, R.E.; Bradbury, R.H. An assessment of the geological evidence for previous Acanthaster outbreaks. Coral Reefs 1986, 4, 235-238. [CrossRef]

8. Moore, R.J. Persistent and transient populations of the crown-of-thorns starfish, Acanthaster planci. Lect. Notes Biomath. 1990, 88, 236-277.

9. Vine, P.J. Crown of Thorns (Acanthaster planci) Plagues: The Natural Causes Theory; Smithsonian Institution: Washington, DC, USA, 1973.

10. Babcock, R.C.; Milton, D.A.; Pratchett, M.S. Relationships between size and reproductive output in the crown-of-thorns starfish. Mar. Biol. 2016, 163, 234. [CrossRef]

11. Endean, R. Report on Investigations Made into Aspects of the Current Acanthaster planci (Crown-of-Thorns) Infestations of Certain Reefs of the Great Barrier Reef; Fisheries Branch: Brisbane, Australia, 1969.

12. Birkeland, C. Terrestrial runoff as a cause of outbreaks of Acanthaster planci (Echinodermata: Asteroidea). Mar. Biol. 1982, 69, 175-185. [CrossRef]

13. Fabricius, K.E.; Okaji, K.; De'ath, G. Three lines of evidence to link outbreaks of the crown-of-thorns seastar Acanthaster planci to the release of larval food limitation. Coral Reefs 2010, 29, 593-605. [CrossRef]

14. Chesher, R.H. Destruction of Pacific corals by the sea star Acanthaster planci. Science 1969, 165, $280-283$. [CrossRef] [PubMed]

15. Pearson, R.G.; Endean, R. A preliminary study of the coral predator Acanthaster plani (L.) (Asteroidea) on the Great Barrier Reef. Fisheries Notes 1969, 3, 27. 
16. Baird, A.H.; Pratchett, M.S.; Hoey, A.S.; Herdiana, Y.; Campbell, S.J. Acanthaster planci is a major cause of coral mortality in Indonesia. Coral Reefs 2013, 32, 803-812. [CrossRef]

17. Pratchett, M.S. Dynamics of an outbreak population of Acanthaster planci at Lizard Island, northern Great Barrier Reef (1995-1999). Coral Reefs 2005, 24, 453-462. [CrossRef]

18. Pan, M.; Hilomen, V.; Palomares, M.L. Size Structure of Acanthaster planci populations in Tubbataha Reefs Natural Parks, Sulu Sea, Philippeans. Fish. Centre Res. Rep. 2010, 18, 70-77.

19. Kenchington, R.A. The crown-of-thorns crisis in Australia: A retrospective analysis. Environ. Conserv. 1978, 5, 11-20. [CrossRef]

20. Lucas, J.S. Growth, maturation and effects of diet in Acanthaster planci (L.) (Asteroidea) and hybrids reared in the laboratory. J. Exp. Mar. Biol. Ecol. 1984, 79, 129-147. [CrossRef]

21. Birkeland, C.; Lucas, J. Acanthaster Planci: Major Management Problem of Coral Reefs; CRC Press: Florida, FL, USA, 1990.

22. Stump, R.J.; Lucas, J.S. Linear growth in spines from Acanthaster planci (L.) involving growth lines and periodic pigment bands. Coral Reefs 1990, 9, 149-154. [CrossRef]

23. Stump, R.J. Age Determination and Life-History Characteristics of Acanthaster planci (L.) (Echinodermata: Asteroidea). Ph.D. Thesis, James Cook University, Townsville, QLD, Australia, 1994.

24. Stump, R.J. An Investigation to Describe Populations Dynamics of Acanthaster planci (L.) around Lizard Island, Cairns Section, Great Barrier Reef Marine Park; Technical Report No. 10; CRC Reef Research Centre: Townsville, QLD, Australia, 1996.

25. Lucas, J.S. Reproductive and larval biology of Acanthaster planci in Great Barrier Reef waters. Micronesica 1973, 9, 197-207.

26. Doherty, P.P.; Coleman, G.G.; Logan, M.M.; MacNeil, M.A. Estimates of the Abundance of the Spawning Stock of Crown-of-Thorns Starfish on the Northern Great Barrier Reef in 2013-2014 and Reflections on the Effectiveness of Starfish Control; Report for the Department of the Environment, Australian Government; Australian Institute of Marine Science: Townsville, QLD, Australia, 2015.

27. Wooldridge, S.A.; Brodie, J.E. Environmental triggers for primary outbreaks of crown-of-thorns starfish on the Great Barrier Reef, Australia. Mar. Poll. Bull. 2015, 101, 805-815. [CrossRef] [PubMed]

28. Vanhatalo, J.; Hosack, G.R.; Sweatman, H. Spatio-temporal modelling of crown-of-thorns starfish outbreaks on the Great Barrier Reef to inform control strategies. J. Appl. Ecol. 2016. [CrossRef]

29. Salvatier, J.; Wiecki, T.V.; Fonnesbeck, C. Probabilistic programming in Python using PyMC3. PeerJ Comp. Sci. 2016, 2, e55. [CrossRef]

30. Ormond, R.T.; Campbell, A.C. Observations on Acanthaster planci and other coral reef echinoderms in the Sudanese Red Sea. Symp. Zool. Soc. Lond. 1971, 28, 3-4.

31. Harrison, H.B.; Pratchett, M.S.; Messmer, V.; Saenz-Agudelo, P.; Berumen, M.L. Microsatellites reveal genetic homogeneity among outbreak populations of crown-of-thorns starfish (Acanthaster cf. solaris) on Australia's Great Barrier Reef. Diversity 2017, 9, 16. [CrossRef]

32. Kettle, B.T. Variations in Biometric and Physiological Parameters of Acanthaster planci (L.) (Echinodermata; Asteroidea) during the Course of a High Density Outbreak. Ph.D. Thesis, James Cook University, Townsville, QLD, Australia, 1990.

33. Engelhardt, U.; Miller, I.; Lassig, B.; Sweatman, H.; Bass, D. Crown-of-thorns starfish (Acanthaster planci) populations in the Great Barrier Reef World Heritage Area: Status report 1995-1996. In Proceedings of the State of the Great Barrier Reef World Heritage Area Technical Workshop, Townsville, Australia, 27-29 November 1995; pp. 158-184.

34. Scheibling, R.E.; Lawrence, J.M. Differences in reproductive strategies of morphs of the genus Echinaster (Echinodermata: Asteroidea) from the eastern Gulf of Mexico. Mar. Biol. 1982, 70, 51-62. [CrossRef]

35. Campana, S.E. Accuracy, precision and quality control in age determination, including a review of the use and abuse of age validation methods. J. Fish. Biol. 2001, 59, 197-242. [CrossRef]

36. Holling, C.S. Some characteristics of simple types of predation and parasitism. Can. Entomol. 1959, 91, 385-398. [CrossRef]

(C) 2017 by the authors. Licensee MDPI, Basel, Switzerland. This article is an open access article distributed under the terms and conditions of the Creative Commons Attribution (CC BY) license (http:/ / creativecommons.org/licenses/by/4.0/). 